Lexis Vol. XLV (2) 2021: 575-622

\title{
Anglicismos y formaciones derivadas en español actual
}

\author{
Félix Rodríguez González \\ Universidad de Alicante \\ frodriguez@ua.es
}

\begin{abstract}
RESUMEN
El objeto de este artículo es doble: por un lado, dar cuenta del enorme $\mathrm{y}$ creciente número de formaciones derivadas a partir de anglicismos que tienen lugar en el español europeo actual; por otro, examinar los distintos patrones derivacionales encontrados, así como las variaciones morfofonológicas, morfológicas y semánticas que conllevan. El artículo aborda, además, el tratamiento lexicográfico seguido en los diccionarios a la hora de dar entrada a este tipo de neologismos. Los datos para este estudio se han tomado principalmente de la prensa diaria de los últimos años y en su mayoría forman parte de los recopilados en el Gran diccionario de anglicismos (2017) y en el reciente Diccionario de anglicismos del deporte (2021). Palabras clave: anglicismo, lenguas en contacto, morfología, derivación, lexicografía
\end{abstract}

Anglicisms and derivative formations in current Spanish

\section{Abstract}

The object of this article is twofold: on the first hand, to give an account of the enormous and growing number of derivatives formed from Anglicisms in present-day European Spanish; and secondly, to examine the different derivational patterns found as well as the morphophonological, morphological and semantic variations involved in them. The article also

https://doi.org/10.18800/lexis.202102.003 
tackles the lexicographic treatment followed in dictionaries when dealing with compound anglicisms. The data have been mainly drawn from the Spanish daily press of the last few decades and they are mostly part of those collected in the Gran diccionario de anglicismos, GDA (2017) and in the recent Diccionario de anglicismos del deporte, DAD (2021).

Keywords: anglicisms, language contact, morphology, derivation, lexicography

\section{INTRODUCCIÓN}

La derivación es un procedimiento de formación de palabras que conduce a un notable incremento del léxico de la lengua mediante la afijación de un morfema (sufijo o prefijo) a una determinada unidad léxica. Tradicionalmente, por lo que respecta a las lenguas románicas, la sufijación se ha venido considerando como un importante medio generador de neologismos, relegando la composición a un modesto segundo plano. No obstante, esta capacidad formativa heredada del latín, en su etapa más moderna, se ha reducido considerablemente a favor de la composición ${ }^{1}$. Tal inversión ha sido subrayada a menudo al considerar el estado de la lengua francesa, pero aun reconociendo esta tendencia, no podemos soslayar las profundas raíces que todavía tiene el proceso derivativo en la lengua actual, no solo en francés, sino, más aun, en las otras lenguas románicas. La lengua española constituye un buen ejemplo a este respecto, ya que figura, a juicio de los especialistas en clasificaciones tipológicas, con un "índice de sufijación” (razón entre el número de sufijos y el de palabras) de .71, el más alto de las lenguas románicas a excepción del sardo (ver Contreras 1972: 102).

En otro lugar ya señalé cómo el proceso de derivación por sufijación alcanza incluso a algo tan estereotipado y extraño morfológicamente como las siglas, lo que constituye una prueba más de la

1 Para un estudio reciente sobre la composición en los anglicismos, ver Rodríguez González (2020b). 
importante presión analógica ejercida por los morfemas finales. En dicho estudio me referí también a los factores de orden extralingüístico, vinculados a los cambios acaecidos en el panorama político en los años setenta del siglo pasado, así como a los condicionamientos de índole estilística y pragmática que condujeron a la proliferación de derivados siglares de variado tipo (ver Rodríguez González 1989: 245). Pues bien, si tales transformaciones tuvieron lugar hace media centuria con un subsistema léxico como el abreviativo, tradicionalmente considerado periférico y marginal, se puede entender la imponente y persistente presencia del mismo fenómeno en los préstamos del inglés de las últimas décadas, tras haberse convertido en uno de los recursos léxico-formativos más importantes de nuestra lengua.

Los derivados más frecuentes son los que afectan a la categoría del nombre y adjetivo, y de manera más esporádica en el verbo. Aplicada al anglicismo, la derivación constituye un índice destacado de su integración léxica. En este artículo voy a limitarme a dar cuenta de la derivación sufijal por su mayor interés como recurso lexicogenésico, estrechamente unido a su función transcategorizadora, lo que no ocurre con los prefijos, que mantienen el lexema resultante en la misma categoría morfosintáctica de partida: por ejemplo, en gay y pregay, ambas formas son sustantivos. Con ello pretendo contribuir a cubrir un hueco en la morfología léxica o derivativa del anglicismo, que suele ser soslayada en la mayoría de las investigaciones.

Los datos para este estudio los he tomado principalmente de la prensa diaria de los últimos años y en su mayoría forman parte de los recopilados en el Gran diccionario de anglicismos, GDA (2017) y en el Diccionario de anglicismos del deporte, DAD (2021), que constan de más de 4.500 y 2.100 entradas, respectivamente. Dada el amplio número de citas ilustrativas escogidas para cada entrada, he prescindido de la documentación de los anglicismos examinados, salvo cuando he añadido alguno más al corpus, en cuyo caso, la referencia aparece señalada en pie de página. 


\section{Categorías y estudio de los Sufijos}

Al pasar revista a los sufijos, seguiré una terminología y una clasificación mixta con criterios sintácticos (en función de la clase de palabra formada — nombres, verbos, etc. — y la clase de la base a la que se afijan —denominales, deverbales, etc.-) así como semánticos. En este punto, y por lo que respecta a los nombres, me referiré a dos grandes categorías, concretos y abstractos, en los que distinguiré diversas subclases que en ciertos casos presentan valores semánticos distintos que dan lugar a derivados polisémicos que se entrecruzan en sus significados, por lo que no se los puede considerar estrictamente como compartimentos estancos. Asimismo, en esta clasificación he aunado y mezclado sufijos de origen y formato inglés con otros de procedencia española.

\subsection{Sufijos nominales}

2.1.1. Nombres concretos. Abarcan categorías semánticas muy dispares como los nombres ocupacionales o de agente, los diminutivos de carácter afectivo (negativo o positivo), los aumentativos que también pueden ser apreciativos o afectivos, y los que expresan la acción verbal (ocupacionales y de agente) o una cualidad o relación.

\subsubsection{Nombres ocupacionales y de agente}

En cuanto a los nombres, predominan los que expresan una ocupación y la noción de agente. El español tiene dos sufijos nominales muy característicos para expresar el concepto de 'el que hace algo', -ista y -ero, que pueden encontrarse reflejados en numerosos préstamos del inglés (futbolista, tenista; rockero, rocanrollero). Igualmente, en inglés son típicos los sufijos homólogos -er e -ist, y también -ster, -ee, man, cuya presencia en nuestra lengua es relativamente menor, pero a los que daré entrada también en este repaso panorámico.

-ER, -ERO

Como sufijo de agente, -er es típicamente inglés, y el más frecuente de todos ellos, por lo que no sorprende que en español un buen número de anglicismos se tomen en préstamo sin cambiar esa 
particular terminación. La mayoría son deverbales con una referencia animada y personal (catcher, hacker, latin lover, dealer, manager, leader/lider, influencer, phreaker, spammer, sprinter, stalker, tagger), otros son derivados referidos a objetos inanimados (best-seller, buffer, bulldozer, cutter, merchandiser, scanner, tester, thriller $)^{2}$. En algunos, como blazer y blister, la acción verbal queda más difuminada. En teenager hay una referencia personal, pero el significado de agente está ausente; también queda perdida en screenager, creado según su mismo modelo.

No faltan derivados que son denominales por añadir el sufijo al nombre en la propia lengua inglesa, antes de introducirse en español como préstamos: baby boomer, blogger, beatboxer, booker, bopper/ boper (< be-bop), breakdancer y breaker (abrev. de breakdancer), challenger, clubber, microblogger. Los hay que no tienen anclaje en el lexema base ni en inglés ni en español, como banner, ni referencia a acción alguna, como bitter ("pseudoanglicismo"3 para un nombre de bebida), camper (tipo de camioneta), bomber y browser (elipsis de bomber jacket y web browser, respectivamente), o la creación autóctona blackandecker (tipo de lesbiana viril). Tampoco la tiene esquiner, que no guarda relación semántica con el sufijo, sino que es una adaptación incorrecta de skin-bead. Referencia personal tiene también croner 'ciclista especializado en pruebas contrarreloj'.

Pese a esta omnipresencia del sufijo en la prensa española, la presión del sistema morfológico induce a menudo a la elección del congénere español -ERO, por encima del más culto -ista. Ocasionalmente, hay vacilación en el uso de -er / -ero (biker/bikero, blogger/ bloguero, fister/fistero, raper/rapero, raver/ravero, rocker/rockero), pero -ero, por su paronimia, se erige en la vía más fácil y natural para sustituir al morfema inglés y, por ende, en un signo claro de

\footnotetext{
2 Neologismo muy reciente es satisfyer [satisfáier], del inglés satisfier 'satisfaciente, satisfactorio', nombre de marca de un succionador de clítoris vendido como productor estrella en España por Amazon durante el último Black Friday. Cit. también en el programa “El Hormiguero" de Antena3 (7-1-2019).

3 Sobre el concepto y extensión del fenómeno del "pseudoanglicismo" en español actual, ver Rodríguez González (2013).
} 
integración de los anglicismos a los que se afija. En estas equivalencias se observa que el derivado español cumple con la doble función sustantiva y adjetival, lo que facilita su sustitución y preeminencia.

Hay también creaciones españolas sin equivalente en inglés, chatero (< chat), choppero (< chopper), clinero (< Kleenex), comixero (< comix), cupcakero (< cupcake), fanzinero, funero (<fun $<$ funboard), googlero (< google), ticketero (<ticket), a las que se puede añadir sandwichera/sangüichera (f. < sándwich) con un significado 'instrumental', referido al aparato que lo prepara. Algunas son utilizadas también como adjetivos: clinero (o klinero), chutero, comixero, cupcakero.

De lo que antecede, se puede colegir que -ero, por su morfología, lleva la ventaja frente al -er inglés de su flexibilidad funcional y tiene casi en exclusiva su valor adjetival. Y subrayo lo de "casi" porque la función de adjetivo la encontrarnos esporádicamente de manera muy singular con el sustantivo rocker (el GDA aporta tres ejemplos) en contextos musicales donde el inglés solo admitiría rock como elemento cualificador en el sintagma correspondiente.

Novedad de lo más singular es el incipiente uso de -er en español, afijado a nombres propios de persona, como sufijo de agente con la significación de 'seguidor o fan de X", siguiendo la estela de rocker (ver abajo). El uso es característico del sociolecto juvenil y tuvo su mayor auge en el fandom musical de los últimos años en países de habla inglesa, y enseguida se propagó por las redes sociales (como Twitter y Facebook). Surgió primero en inglés, con ejemplos influyentes como believers y directioners (para referirse a las fans del cantante canadiense Justin Bieber y del grupo musical One Direction), pero enseguida encontró imitadores en nuestro solar patrio extendiéndose su aplicación a otros contextos sociales y políticos. Del perfil sociológico y lingüístico de este fenómeno se ha ocupado Roig-Marín (2016) en un excelente estudio monográfico donde cita numerosas formaciones, bien que efímeras, como Abrabamers, Casanovers and Alboraners, en alusión a las fans de los cantantes Abraham Mateo, Casanova y Pablo Alborán, respectivamente, y errejoners, garzoners, pabloners, riverers, en referencia 
a fans de los jóvenes protagonistas de la nueva política española, como Íñigo Errejón, Alberto Garzón, Pablo Iglesias y Albert Rivera. Estos ejemplos muestran a las claras la apropiación e internalización en nuestra lengua de un sufijo de proveniencia inglesa, como -er, aplicado a un léxico que va más allá del entorno del anglicismo, y más propicio para marcar la expresividad que -ero dentro del lenguaje juvenil. Aunque funcionalmente equivalentes, por su polisemia el morfema español comparte riesgos de ambigüedad que no presenta -er, que, además, al ser un morfema no marcado en cuanto a género gramatical, ofrece una ventaja a los hablantes sensibilizados con la cuestión del sexismo y del género inclusivo ${ }^{4}$. Por otro lado, desde el punto de vista fonológico, pese a la inclinación del español por una silabación natural del tipo $\mathrm{CV}-\mathrm{CV}$, la secuencia C+s no ha sido óbice para la importación del morfema del plural inglés con los anglicismos (ver Rodríguez González 2017a). En el caso específico de -ers, al menos a los hablantes de las regiones catalana y valenciana les resulta más fácil su asimilación por encontrarse con formas autóctonas en la lengua diaria, como consellers ('consejeros'), botiflers ('colaboracionistas') y caganers ('cagones', tradicional figura de los belenes en Cataluña).

-ERO /-ISTA

En español -ero tiene un uso más popular y como tal aparece con frecuencia ligado a nombres tradicionalmente asociados con un menor prestigio social, como barrendero, camionero, churrero, cocinero, al igual que el cuasihiperónimo o genérico obrero. Esta connotación puede verse hasta cierto punto también en derivados de anglicismos, como bisnero 'persona que hace business o negocios, generalmente ilícitos y en la calle', y los citados antes choppero (o chopero), 'conductor de motos o bicicletas de tipo chopper', comixero 'vendedor de comix', clinero 'vendedor de kleenex' y ticketero 'expendedor de tickets o billetes'.

\footnotetext{
4 Sobre la introducción del sufijo - er en español, ver también Rodríguez González
} (2020a). 
Igualmente es frecuente la aparición del sufijo en contextos marginales y juveniles con referencia a intérpretes o practicantes de estilos musicales, como bluesero, folkero, popero, punkero, rapero, reguetonero, soulero, sin duda influidos por el peso analógico de su congénere rockero (o roquero). También, en el campo marginal, bedesemero 'practicante del bdsm' y pulpero (relativo a la pulp fiction).

Además de -ero, -ista sobresale en español como un sufijo agencial productivo que contrasta con la escasez de formaciones calcadas del inglés -ist. En efecto, excepto chartista (< chartist), todos los derivados en -ista se han formado en la propia lengua y tienen equivalencias anisomórficas en inglés: por ejemplo, tenista y futbolista traducen el inglés tennis player y footballer. Con voces patrimoniales -ista tiene una connotación más positiva que -ero, de lo que son ejemplos accionista, electricista, guionista, oficinista, y en el terreno musical designaciones alusivas a la persona que toca algunos instrumentos (bajista, guitarrista, trompetista). Con anglicismos es muy productivo con nombres de practicantes de todo tipo de modalidades deportivas, entre otros, basquetista, beisbolista, crolista, crosista y ciclo-crossista, harleyst/harlysta, surfista, tenista, waterpolista, windsurfista, acuñados por analogía con el más frecuente, antiguo y prestigioso de futbolista, así como el más genérico de deportista ${ }^{5}$. Como excepción puede citarse BMXero 'ciclista que practica el BмX' (modalidad de competición de bicicletas).

-MAN Sufijo nominal inglés con significado masculino derivado de su propia etimología, lit. 'hombre' y cuya base léxica es asimismo un nombre. Por ejemplo, cameraman ('hombre encargado de manejar la cámara cinematográfica', cuyo uso ha quedado obsoleto frente al empuje de sus equivalentes nativos: cámara, camarógrafo y operador de cine/de televisión). Aparece con frecuencia en préstamos relacionados con el entretenimiento, la música y el

\footnotetext{
5 La connotación positiva del sufijo español -ista contrasta curiosamente con la negativa o despectiva de los préstamos del español en el inglés como alternativa al más neutro -ist (ver Rodríguez González 1995).
} 
ocio: barman, bluesman, clubman, deck-man, frontman, funkman, gagman, jazzman, showman, soulman, stuntman. Todos ellos tienen su correspondiente flexión en femenino, -woman, aunque, por condicionamientos sociológicos, con algunos conceptos esta forma no es tan frecuente. En superman, que el inglés calcó del alemán Übermensch, lit. superhombre', la base es un adjetivo, y con el femenino superwoman mantiene diferencias semánticas y contextuales: supermán tiene un uso más general, designa al 'hombre dotado de fortaleza o habilidades extraordinarias'; superwoman, aunque creado por analogía con la forma masculina, se emplea en el campo de la sociología y la psicología para referirse a la 'mujer dotada de capacidades excepcionales, capaz de compaginar su carrera profesional y su vida privada, lo que le convierte en el ideal feminista'. Derivado con el significado de agente es también guachimán, regionalismo canario con el significado de 'encargado de una obra en construcción', por adaptación del préstamo directo watchman, lit. 'guardián'.

Todos estos nombres tienen en común una referencia personal, excepto walkman 'pequeño radio transistor que permite oír música mientras se camina', que es un nombre comercial, al igual que discman 'aparato portátil de compact disc', formado por analogía.

-EE En inglés tiene una presencia relativa, y menos como sufijo agente. El anglicismo más frecuente en español es referee [referí], utilizado como forma obsoleta en el contexto del fútbol y otros juegos de pelota, sustituido hoy por 'arbitro'. En la jerga académica, designa el 'investigador que es consultado para emitir un juicio sobre un artículo que pretende ser publicado en una revista especializada, o sobre los méritos de un aspirante a una beca'. Con este segundo significado, el español cuenta con sinónimos equivalentes, como censor, revisor anónimo, revisor científico, revisor externo (ver GDA).

Salvo referee, los anglicismos en español con este sufijo conservan el significado pasivo característico del léxico inglés, como reflejan las voces coachee 'persona o pareja que recibe clase o entrenamiento de un coach' y mentee, que en la jerga económica 
designa a la 'persona que desarrolla sus competencias profesionales con ayuda de un mentor, dentro de un proceso de mentoring'. En ambos casos su presencia es esporádica.

También es característica del inglés su acentuación oxítona. En referee, sin embargo, su mayor uso ha conllevado una variación acentual tal y como reflejan la transcripción fonética que le da el Diccionario Oxford Inglés - Español ['refd'ri] y la variante argótica refli, registrada por León (1980).

-STER Sufijo denominal típicamente inglés que se refiere a un agente con referencia personal o inanimado. La voz más conocida es gangster 'miembro de una banda criminal o grupo mafioso', que por significado provee de un sentido peyorativo a la mayoría de las voces creadas por analogía. Así, bankster puede ser considerado un cruce de banker y gangster, y se refiere al 'banquero corrupto'; beatster es un beatnik, pero utilizado despectivamente ${ }^{7}$; draster es una adaptación de drugster, formado a partir de drug 'droga's. Hipster es una persona de comportamiento marginal y con gran afición al jazz, convertido en la última década en un miembro de una subcultura de clase media urbana a la que pertenecen personas relacionadas con un ambiente bohemio. Su creación ha partido de la base hip 'que está a la moda' y de algún modo evoca la etimología y uso de hippie.

Algunas creaciones con este mismo sufijo denotan objetos inanimados, carentes de toda referencia personal y donde el significado de agente no es tan aparente. Como ejemplo vale citar dragster, que en automoción se usa como un coche de carreras, a partir de drag 'arrastrar', y roadster, que en el uso masculino es un tipo de coche ('descapotable biplaza') y en femenino un tipo de motocicleta.

\footnotetext{
6 Los "banksters" nunca ven satisfechas sus ansias de acumular. (Juan Carlos Valero, "Banksters y los que arriman el hombro", $A b c$, Barcelona, 17-7-2012).

7 Jacl Kerouac describió a los "beatsters" de 1948 como unos sabios lacónicos y barbudos que bebían cerveza escuchando jazz y hop en locales "beats”, rodeados de unas chicas silenciosas vestidas rigurosamente de negro (El Mundo Magazine, 4-12-1993, 62). 8 Draster. Toxicómano, drogodependiente, colgado, drogota. Citado en Ramoncín (1993).
} 
-IE Sufijo denominal característico del inglés, pronunciado siempre [i]. Generalmente va unido a sustantivos (folkie, groupie, grungy, roadie, rookie, veggie, yonquie -más conocido en su forma adaptada yonqui-, yuppie) y, ocasionalmente, a una raíz verbal (walkie-talkie) o adjetival (oldie). Tanto en inglés como en español alterna con la variante gráfica -y (folky, groupy, yonky, yuppy).

Algunas de estas creaciones léxicas tienen doble función, nominal y adjetival, como folkie 'relativo a la música folk' y 'cantante de estilo folk' (como sinónimo de folk-singer), punky (< punk). También la tienen veggie 'vegetariano' y foodie, 'referido al aficionado a la comida (food) y a la bebida, y muy interesado en todo lo concerniente a las noticias y novedades sobre su consumo y preparación'; y la abreviación yuppie, cuya base es una sigla, YUP ('young urban professional).

En trekkie, la base es verbal en el contexto deportivo (to trek 'practicar una excursión o marcha a pie por caminos largos y difíciles') y también nominal, en la jerga del espectáculo, como 'entusiasta de la serie televisiva Star Trek. Caddie, que en el golf significa 'persona que lleva la bolsa con los palos del jugador y también le asesora', alterna con caddy y también con cadi, carece de una base, aunque etimológicamente remite al francés cadet, lit. 'el hijo menor, segundón’). Originariamente el ayudante del jugador era un muchacho, de ahí el nombre.

La mayoría de los derivados con -ie tienen una referencia personal y, en todo caso, designan objetos animados (caso de yorkie); solo excepcionalmente se refieren a objetos (walkie-talkie, oldie). No ocurre lo mismo con braggie y dronie, cuya terminación es engañosa, pues en realidad se han acuñado sirviéndose de la analogía y de la significación de selfie.

-DOR Sufijo de agente típicamente español, derivador del latín -tor, que se une fácilmente a cualquier préstamo de base léxica verbal. Siguiendo el curso de los verbos que le sirven de base, la más frecuente es la terminada en -ear: bateador (< bate 'bat'), bisneador (< bisnear < business), boxeador (< boxear < box), chateador $(<$ 
chat), impiechador (< impiechar), noqueador (< noquear 'to knock out'), rapeador (<rapear), zapineador (< zapinear < zapping), pero también se registran algunas con el sufijo -ar: chutador (<chutar), filmador < filmar), flipador (< fipar).

Emparentado morfológicamente con -dor está el sufijo $\rightarrow$ TOR, que unido a la terminación de la base léxica que le precede forma la secuencia -ator, de formato y origen inglés y pronunciado conforme a la fonética de esta lengua [éitor]. Se añade a algunas voces españolas y les confiere un matiz claramente humorístico: acojonator, adjetivo, por 'acojonante', buitrator [buitréitor]' como sinónimo de 'buitre', por analogía con terminator 'terminador', el más conocido de la serie.

Terminator procede de un personaje de ciencia ficción dotado de poderes sobrehumanos y gran capacidad destructora. Por su frecuente uso, se utiliza también en sentido figurado con la significación de 'persona que sobresale por encima de los demás en una actividad' como sinónimo de supermán y fuera de serie. Ocasionalmente tiene un uso peyorativo. En el lenguaje periodístico también se ha registrado con la adaptación gráfica termineitor (ver $G D A)^{10}$.

A diferencia de -dor, donde la función transcategorizadora del sufijo es clara, pues todas las bases verbales se convierten en sustantivos, en los casos antes mencionados que siguen el modelo de terminator la función gramatical — sustantiva o adjetiva- permanece idéntica y solo cambia la connotación. De este modo pueden considerarse como derivados "parasitarios", siguiendo un proceso análogo al recorrido por la sufijación -ATA, -ETA y -OTA con voces nativas en español, como droga $\rightarrow$ drogata, drogueta, drogota.

Estos sufijos se repiten también con bases léxicas de origen inglés, como flipeta (<flipe, flipar), hardcoreta (< bardcore), punketa $(<$ punk), windsurfeta (<windsurf) y flipota (flipe, flipar) y esnifota

9 - ¡Tú te entregas a la policía, Grisi [...] antes de que se presenten aquí con todos los buitrators de la prensa detrás y me hundan la carrera! (Fernández 1992: 139).

10 El sufijo -(a)tor vuelve a aparecer con sobrenombres efímeros derivados de nombres propios utilizados en el lenguaje juvenil propio del fandom musical, como arianators (fans de Ariana Grande), selenator ( $<$ Selena Gomez), sheeranators ( $<$ Ed Sheeran) (Citado por Roig-Marín 2016: 190). 
(< esnife, esnifar), empleados en ambientes juveniles y marginales. Ejemplos similares con este tipo de derivación son los basados en el sufijo de origen vasco -ARRA, como punkarra (<punk), yonkarra (< yonkie), y el más reciente -ULO (yonquirulo < yonki, yonqui) 'yonqui de aspectos andrajoso', que evoca el más difundido de machirulo (de origen incierto, suele atribuirse a la asociación con 'macho' y 'chulo') con el que comparte el uso de una /-r-/ intervocálica de apoyo. No parece constar en español un sufijo -rulo, pero existen voces con esa terminación utilizadas despectivamente en variedades coloquiales del español, como garrulo 'tosco', sapirulo 'regordete' (en El Salvador), paparulo ('torpe', 'ignorante', en Argentina), entre otras (ver Grijelmo 2019: 172). Probablemente, la etimología nos lleva al sufijo latino de carácter diminutivo y despectivo -ulus (rex > regulus 'reyezuelo', porcus > porculus 'cerdito')

-or Derivado del latín -or, -oris, indica cualidad, pero también agente (por ejemplo, revisor). Con anglicismo he registrado estresor 'actividad que produce estrés' (< stress).

-ONGO La terminación -ongo como sufijo en español con una referencia personal es rara, pero está presente en algunas voces castizas con un matiz despectivo y humorístico, como bailongo ${ }^{11}$ y frailongo ${ }^{12}$. Junto a otras con similar morfología, como -engo, -ango, -engo, Juan Selva (1949) la incluye dentro de un grupo que calificó en su día como "sufijos olvidados", a los que atribuye raíces africanas. Con anglicismo el GDA registra una voz, jevilongo, 'aficionado al heavy (metal)' e 'intérprete de este estilo', y tiene valor de nombre y adjetivo al igual que rockero, de la misma serie semántica musical. La /-l-/ intervocálica ofrece apoyatura al sufijo, y probablemente voces como las señaladas, bailongo y frailongo, han servido de modelo en la derivación.

11 Julián \{Julián Muñoz, ex alcalde de Málaga], como decimos, siempre fue muy bailongo... (Marta Cibelina, "Famosos / El Purgatorio", Español.com, 27-1-2018, 01:16). 12 La suerte se me cayó al pozo. Un frailongo y con los aperos de labranza. ¿Será cateto o vicioso? Ora et labora. Veamos como labora (Alfonso Zurro, Farsas Maravillosas, Ediciones Jácara [Sevilla], 1987, p. 51). 


\subsubsection{Sufijos apreciativos}

Si por "derivación" se entiende el procedimiento de formación de nuevos signos lingüísticos mediante la adición de un afijo a un significante, de modo que el nuevo significante posea un significante diferente del originario, parece, en principio, que la formación de diminutivos no puede incluirse en la derivación, puesto que no da lugar a nuevos significados, sino a una "alteración" cuantitativa o emocional del significado originario. Por ello, desde hace tiempo las gramáticas italianas utilizaron la denominación "alterazione" para designar la sufijación diminutiva y distinguirla de los demás sufijos (ver, por ejemplo, Tekavčić 1972: 78). Igualmente, por lo que respecta a la lengua española, y con anterioridad, Rafael Lapesa dejó clara su postura inequívoca en este sentido mostrándose abiertamente contrario a incluir los diminutivos dentro de la derivación, aunque mantiene el término "sufijación”, según su ponencia en el II Congreso de Academias de la Lengua: "Como accidente gramatical del nombre se añadirá al género y al número la sufijación apreciativa (diminutivos, aumentativos y despectivos) que, a diferencia de la derivación no origina de ordinario palabras nuevas, sino formas indicadoras de magnitud o afecto" (citado por González Ollé 1962: 269).

Partiendo de estas premisas, las gramáticas castellanas no suelen colocar la formación de diminutivos en la derivación, pero tampoco la separan de ella en cuanto a que hablan de sufijos diminutivos y de sufijación diminutiva, incluyendo a esta dentro de una categoría más general con el nombre de "apreciativa" (ver, por ejemplo, Lang 1992: 35).

\subsection{Diminutivos}

Un tipo especial de derivados encuadrable dentro de los nombres concretos es el formado por los diminutivos. Con anglicismos destaca la sufijación apreciativa o hipocorística marcada por los sufijos -illo e -ito, los más comunes en español y virtualmente afijables a cualquier sustantivo, sobre todo si cuentan con un gran uso. En el GDA se registran con-ILLO wondercillo, con ligero acor- 
tamiento de la base (<wonderbra), y con -ITo bikinito (< bikini), jerselito y jerseyito (< jersey). Pero también podríamos pensar en jersecillo y suetercillo (a partir de sueter < sweater). Con fulbito y futbito, variante de fúlbol/fútbol, y con futbolín, que contiene el también diminutivo -ín, la diferencia de significado es denotativa, en ambos casos relacionada con la idea de 'pequeñez'.

El significado de tamaño menor referido a nombres en inglés se transmite inequívocamente mediante los sufijos -LET, derivado en último término del francés -ETTE. Ambos están representados con los anglicismos starlet actriz joven, que alterna con la grafía francesa starlette, y filmlet, pseudoanglicismo usado en el pasado para designar un 'cortometraje breve con contenido publicitario'. Precisamente el sufijo francés -ette está bien presente en el préstamo del inglés kitchnette 'antecocina' (lit 'cocinita', cocina de pequeñas dimensiones) que, a diferencia de las dos voces anteriores, ha conservado la pronunciación oxítona. También se documenta en los sociolectos juveniles y marginales, de lo que dan testimonio las voces punkette 'chica que pertenece al movimiento punk o sigue su moda', vampettes ('fans de vamps') y juggalettes (chicas fans de la banda Insane Clown Posse, a partir de su canción The Juggla $)^{13}$.

-ETo Sufijo diminutivo de carácter despectivo español que se ha afijado a voces ya muy establecidas, como bareto $(<$ bar), casi irreconocible como anglicismo, y pafeto (paf, variante de pub basada en su pronunciación coloquial).

-Y/-IE Es un sufijo hipocorístico que se emplea para formar nombres de personas o animales así como adjetivos. -ie originalmente es variante tomada de la ortografía escocesa (ver Zandvoort ([1957] 1972: 303). Atrás lo vimos con una referencia ocupacional o de agente, con función transcategorizadora, pero funcionalmente es asimilable también a los diminutivos, con significado afectivo. Ejemplos son el nombre daddy 'papito', fatty 'gordi' (persona gorda), también utilizado como adjetivo. Aparece también como

13 Top Music E Cine, 172, 6. Citado por Roig-Marín (2016: 191). 
morfema final con truncamientos: yorkie, un truncamiento $(<$ yorkshire terrier); Aussie 'australiano' (< Australian; movie [múbi] (< moving pictures) 'película'.

-UELO Diminutivo que tiene su origen en el latín -olus y tiene un valor afectivo o despectivo (pobre $\rightarrow$ pobrezuelo). Con anglicismos aparece en hippiuelo, con valor nominal y adjetival, en la pluma del novelista Terenci Moix 1990, El peso de la paja, quien lo cita en los siguientes textos:

“Al punto llegó Vince, el criado hippiuelo de Livio [...]” (p. 26) "Y el hippiuelo, con ojos todavía adormilados, iba de un lado para otro [...]” (p. 29)

-Ulo Igualmente, el sufijo tiene su origen en el latín -ulus, que tiene un valor diminutivo (Pharies 2002: 523) y despectivo (rex $\rightarrow$ regulus 'reyezuelo', porcus $\rightarrow$ porculus 'cerdito'). El GDA registra la voz yonquirulo < yonki, yonqui 'yonqui de aspectos andrajoso', que evoca el más difundido de machirulo (de origen incierto, para algunos un cruce asociativo de 'macho' y 'chulo'). Aparte, cabe citar funkyrulo $(<\text { funky })^{14}$, hippirulo ${ }^{15}$ y punkirulo ${ }^{16}$, todos ellos procedentes del lenguaje juvenil y marginal y registrados en los foros de internet. No parece constar en español un sufijo -rulo, pero existen voces con esa terminación utilizadas despectivamente en variedades coloquiales del español, como garrulo 'tosco', sapirulo 'regordete' (en El Salvador), paparulo ('torpe', 'ignorante', en Argentina), entre otras (ver Grijelmo 2019: 172). Probablemente la /-r-/ intervocalica sirve de apoyo y conexión a la base con el sufijo al tiempo que proporciona al derivado adjetival una silabación más natural y lo hace más eufónico, tal como ocurre con la

\footnotetext{
14 Parece que es un poco más funkyrulo que un Jazz Bass (https://bajistasonline.es/ forum/viewtopic.php?t=11085).

15 Hace falta un pacifista hippirulo entre tanto caza guerrillero para compensar. Tomado de <https://www.miliamperios.com/foro/pilatus-porter-hippie-139496> (Consultado el 16 de octubre de 2009).

16 Recuerdo que la hija de unos amigos empezó a ir con unos punkirulos y a consumir cannabis. Tomado de <https://www.lamarihuana.com/foros/threads/ elecciones-europeas-iniciativa-internacionalista.77066/page-2>.
} 
/-t-/ en lobbytear. En casos como estos, W. Meyer-Lubke habla de "elemento de enlace", "sonido transitorio" o "antihiático", y, de una manera más genérica, Malkiel (1958) los denomina "interfijos” y “antesufijos" (ver Martínez Celdrán 1978: 448-449), pero que este proceso fonológico no es obligado lo confirma la voz bippinelo mencionada antes, donde las tres vocales /-iue-/ forman una secuencia de lo más insólita.

\subsection{Aumentativos}

-on Sufijo aumentativo, del latín -o, onis, que se añade a un nombre para marcar un mayor tamaño (casa $\rightarrow$ casón), pero también es apreciativo, pues puede marcar expresividad. Con anglicismo está presente en leatheron, que sustituyó a leatherman, ambas formas obsoletas hoy que dieron lugar a lederón, -ona, adaptadas y popularizadas por el escritor Eduardo Mendicutti. Designa al gay que siente fetichismo por el leder (< leather) o cuero o es sadomasoquista, y a su difusión ha contribuido la asociación con maricón/ maricona, lo que les da un matiz humorístico. Lo importante del neologismo en su forma adaptada es su irradiación, pues ha tenido su continuación con otras formas expresivas, como lederonga, con el sufijo -onga, que aporta un matiz despectivo por asociación con voces como machonga, putonga, guarridonga. También es remarcable el sufijo -ina, con lederina, en el otro extremo de la escala afectiva, que designa al 'joven afeminado con gusto por el cuero, pero en plan blando, suave'. Conviene subrayar que estas últimas voces tienen una referencia masculina ('gay'), pese a su flexión femenina, una aparente discordancia gramatical muy propia del estilo "camp" tan característico de la literatura gay. Diferente es el caso de elfina, derivado femenino de elfo, término de la mitología germánica y escandinava.

-Azo Sufijo aumentativo utilizado ocasionalmente con anglicismos para expresar una acción abrupta, explosiva, por analogía con otras formas en -azo como cañonazo, pistoletazo. Los ejemplos registrados, si nos atenemos al punto de partida, son indudablemente denominales: chutazo (< chute), claxonazo (< claxon), flashazo 
$(<$ flash $) /$ flasazo $(<$ flas), flipazo (<flipe), frikazo, lookazo (<look), pilazo (< pill), popperazo (<popper) en efecto, se han formado a partir de nombres, pero en su conformación el sema más sobresaliente, 'acción', evoca igualmente la existencia de los verbos emparentados morfológicamente con ellos: chutar, claxonar, flashear/flasear, flipar. González García (2019: 636) aporta derivados en español actual utilizados para aludir a protestas cívicas reivindicativas, entre los cuales figuran tuiterazos y tuitazos, de tuit ('envíos masivos de protestas en las redes sociales').

\subsection{Despectivos}

-ACo Del latín -acus, procedente a su vez del griego akós, marca relación y es despectivo. El único derivado registrado es usaco, utilizado por Carlos María Ydígoras en su novela Los usacos (Madrid, 1967), donde el sufijo fue utilizado humorísticamente. A pesar de la referencia irónica del nombre, en el texto constituye una denominación ficticia que responde a las iniciales de Unión de Satélites Autónomos. Compañía de Opulencia Soberanos (p. 440). No obstante, -aco cuajó como sufijo de caracterización para referirse al habitante de USA, o sea, el 'norteamericano', y así fue utilizado a partir de entonces en la prensa. Lo usó por ejemplo un lector en "Contra Somoza" (Cartas al Director), El País, 12-7-1989, p. 8) y todavía hoy aparece en blogs en frases como "propaganda USACA".

El sufijo ha vuelto a aparecer recientemente dentro del lenguaje juvenil y marginal con espitaco 'anfetamina' (< espit < speed) y toyaco, empleado despectivamente como sustantivo para referirse al 'grafitero novato', a partir del inglés toy 'juguete', pero también, por extensión, como adjetivo, 'de mala calidad' (por ejemplo, "canciones toyacas", ver $G D A$ ).

-ORro Sufijo despectivo que añade una connotación negativa al nombre al que se une (por ejemplo, abejorro). Como anglicismos el corpus incluye skinorro, derivado de skin.

Como lo del coming-out ya queda bien y vivimos en una época de corrección política, discriminar a los gays sólo cabe en la neurona de un skinorro (Primera Linea, nov. 1998, 62). 
A estos se pueden añadir a algunos más infrecuentes, como -uelo, -ulo y -arra, mencionados antes.

\subsubsection{Sufijos locativos y colectivos}

-ERía Formado por la unión de los sufijos -ero e -ía, aparece con algunos anglicismos que denotan el lugar donde se expenden los productos asociados con la base léxica, por ejemplo, bebidas como en whiskería, coctelería, por analogía con 'cafetería', sandwichería, y libros como comiquería, por fluencia de 'librería'. Con nursería, a partir de nurse 'mujer encargada de cuidar a los niños en la casa de estos', se han creado varios usos con sentido locativo ('cuarto de los niños', 'sala de un hospital donde se cuida a los bebés recién nacidos', y en un zoo 'cuarto donde se cuidan a las crías recién nacidas'). Otro de los sentidos del sufijo en español es el colectivo, como en jeanería ${ }^{17}$, empleado para referirse al conjunto de tiendas donde se venden pantalones vaqueros o jeans. Ambos sentidos, el locativo de carácter concreto y el colectivo de significado abstracto se juntan en gayería 'lugares de ambiente' y, por extensión, 'conjunto de gays', aunque predomina el primero, al igual que ocurre con judería ('lugar donde habitan los judíos').

-ERío Del latín -ivus, indica un colectivo, un 'conjunto de cosas o personas', con un matiz despectivo (por ejemplo, griterío), pero también una 'cualidad' (por ejemplo, niñerio). Con anglicismos es poco productivo, pero se pueden ver ambos valores con freakerio, 'conjunto de personas freak' y también como 'cualidad de freak'. El valor colectivo se muestra más palpablemente en draguerio 'conjunto de drags' y en el regionalismo chonerío, que en Canarias se refiere al 'conjunto de turistas anglosajones o procedentes de otras partes del centro y norte de Europa, a partir de choni 'turista de origen inglés' (del inglés Johnny 'juanito'). Un estudio monográfico sobre los valores de ese sufijo, puede verse en Zacarías (2016).

\footnotetext{
17 Todo está más barato, hasta las casas de masaje, la jeanería con patas de elefante y las cremas de sol (Raúl del Pozo, El Mundo, 10-7-2009, 64).
} 
-ERA Sufijo nominal empleado a veces para dar un carácter colectivo a las voces así formadas. En otro lugar (Rodríguez González 1989: 235), al examinar la derivación de las siglas en español, me referí al ejemplo humorístico de pecera, que incluía también un sentido locativo al referirse al lugar de reunión de militantes del PCE. Con anglicismos, estos dos sentidos se entrelazan en formaciones como coctelera, tanto en su sentido básico inicial ('recipiente donde se mezclan los componentes de un cóctel') como en su uso figurado ('mezcla de cosas distintas'), y chequera ('cartera para cheques'), proceso en cierto modo similar al que más tarde ofrecería disquetera 'unidad de disco empleada para leer datos en disquetes'). Distinto es el sentido y el proceso que condujo a beisbolera, pues denota un objeto único e indivisible, una prenda de vestir ('gorra beisbolera'), como se registra en el GDA, pero también una 'chaqueta beisbolera', asociada en su origen con los jugadores de béisbol; en ambos casos, la voz es fruto de una sustantivación del adjetivo (beisbolero) con flexión femenina resultado de la elipsis.

\subsubsection{Sustantivos postverbales}

-ADA Sufijo que se añade a voces verbales pera indicar una 'acción': esnifada (< snif, 'aspiración por la nariz de cocaína u otra droga), flipada ('acción de flipar'), surfeada (en el surf, 'deslizamiento sobre una ola'), freakada ('cosa rara, anormal, excéntrica'; por cruce híbrido de freak y palabras españolas terminadas en -ada como tontada, burrada, etc). De manera análoga a partir estrictamente de un nombre se ha formado esnobada ('tontería propia de un esnob').

-ADo Sufijo empleado en la flexión gramatical para formar participios. Algunos usos son de tipo derivativo como baneado 'acción de banear', escaneado 'acción y efecto de escanear'; 'escaneo', esnifado 'acción y efecto de esnifar'.

-ING Es un sufijo muy característico de la morfología inglesa, tanto la gramatical (gerundio) como la léxica o derivativa, donde encierra diversos valores semánticos siendo el postverbal el más típico de 
ellos $^{18}$. En el léxico español de origen inglés es muy productivo al adjuntarse a múltiples verbos para indicar la acción relacionada con la base (airbag $\rightarrow$ airbagging, step $\rightarrow$ stepping, stretch $\rightarrow$ stretching). En ocasiones el préstamo inglés se ha tomado directamente como sustantivo (jogging, training), y, excepcionalmente, incluso tras haberse saltado ese proceso en la propia lengua inglesa, como en footing (del nombre foot), sinónimo de jogging, en este caso se le considera un típico pseudoanglicismo, ya que en inglés carece de tal significado. Desde que el sufijo entrara con fuerza en la lengua española y llamara especialmente la atención de la hispanista Ana María Vigara (1999), que le dedicó un 'cajetín' en la revista de la Universidad Complutense con el título de "cañoning", se ha producido un aluvión de formas con -ing - 379 en este corpus - adjuntándose incluso a sustantivos españoles sin siquiera raíz inglesa, como en los usos humorísticos puenting, balconing, edredoning, silloning. En ocasiones, cumplen la doble función de nominal y adjetival (como antidumping, antifading). Singular es la importación de un mero uso adjetival, como expecting, lit. 'en espera', forma eufemística aplicada a una mujer embarazada, que recuerda nuestra perífrasis '[mujer] en estado de buena esperanza'. En browning 'pistola automática', no hay propiamente sufijo, sino que la terminación está tomada del nombre de su inventor, John B. Browning (1855-1926).

Como cabría esperar, la Academia desdeña esta construcción tan exótica para nuestra morfología, prefiriendo por ejemplo el sufijo -eo de zapeo, de raigambre española (por ejemplo, abucheo, mariposeo) a zapping, por más natural, pero el esnobismo patrio se ve incapaz de resistir esta tendencia. El texto siguiente es de lo más ilustrativo:

Se acabó eso de chatear por Tinder sin sacar una cita en persona. [...] Los solteros se han cansado del ligoteo virtual: del ghosting, del icing, del simmering y todos esos noséquéing con los que el

\footnotetext{
18 Sobre los distintos aspectos lingüísticos (gramaticales, fonéticos, ortográficos, morfológicos y semánticos) sobre el sufijo -ing en español, ver Mott (2015). Sobre la difusión y variedad de usos de -ing, ver también Coll (2007).
} 
ligue de turno se evapora -ipluf!- en el mundo virtual. En estas nuevas aplicaciones, los miembros solo se apuntan cuando están disponibles esa misma noche para quedar ("Lo más: Ligarás en la vida real”, El Periódico de Catalunya, 5-1-2018).

El aroma inglés que destila esta grafía y el prestigio que le acompaña es tal que son contados los anglicismos en los que la presión del idioma conduce a formas adaptadas en -in (chutin, dopin, drinkin, esmoquin, estrikin/estriquin, futin, holdin), pero incluso en estos casos no pasan de ser alternativas estilísticas carentes de estabilidad. Por esa razón en el GDA aparecen postlematizadas, tras el lema principal, y pocas veces reciben entrada aparte.

\subsubsection{Nombres abstractos}

-ISMO Sufijo muy usual en el vocabulario político y social para designar una doctrina, una realidad o una actitud. Aparece asociado al sufijo $\rightarrow$ ista, con el que forma pareja desde sus comienzos. Los neologismos así formados son de carácter culto pero de uso muy restringido y relegado casi a la lengua literaria, sin embargo la "frecuencia léxica" de los -ismos es relativamente alta:

autostopismo, besellerismo/bestsellerismo, boy-scoutismo, brokerismo, bullionismo, chartismo, campismo, computerismo, dandismol dandismo, dragqueenismo, fashionismo, freakismo, gangsterismo, bipsterismo, hooliganismo/juliganismo, lobbysmo/lobbismo/ lobismo, macartismo, maltusianismo, punkismo, revivalismo, scoutismo, trade-unionismo, yeyeismo, yonkismo, yupismo/yuppismo, zapinguismo.

Existen algunos -ismos, como daltonismo, darbismo. darwinismo, escortismo ${ }^{19}$, que se han producido por adaptación directa del inglés (daltonism, darbism, darwinism, escortism).

-IDAD Sufijo empleado en formaciones de carácter culto para indicar una cualidad. El único anglicismo con esta derivación es serendi-

19 Por mucha discreción que echaran al escortismo "la profesión más antigua del mundo" [...] nadie cree que no supieran lo que sucedía pared con pared (F. Jiménez Losantos, “Las cuatro esquinas”, El Mundo, La Otra Crónica,10-10-2020, 19). 
pidad 'facultad de descubrir algo importante de manera imprevista', que alterna con serendipia, y que se ha formado por adaptación del inglés serendipity.

-ITUD Al igual que el anterior, expresa una cualidad o condición, como en punkitud (< punk). El término punkitude también se documenta en francés en 1977 (ver Colin/Mével 1990).

-AJE Sufijo empleado con frecuencia en español para expresar el resultado de una acción, como aterrizaje (de aterrizar), aprendizaje (de aprender). Este mismo sentido puede suponerse en las voces clampaje 'pinzamiento mediante un clamp' (pinzas empleadas en cirugía), stockage/estocage, pseudoanglicismo utilizado en la jerga comercial para referirse a 'productos o mercancías en almacén', donde la acción verbal está sobreentendida. Se trata de dos préstamos del francés, clampage y stockage, formados a partir del inglés clamp y stock ('existencias, almacenamiento, inventario') y el sufijo francés -age. También cabe citar desestockaje, forma parasintética (des + stockage, para referirse a la 'acción y efecto de dar salida a las mercancías almacenadas'). Otras voces con esta terminación son brokerage 'operación financiera realizada por medio de un broker', dopaje (a partir de doping) y yuppillage 'corrupción de la clase tecnocrática y gobernante', empleada con sentido humorístico en la prensa política; en este caso, sin embargo, la presencia de la -ll- me ha llevado a interpretarla como un cruce de yuppi $(<y u p p y)$ y el español pillaje.

-EZ Sufijo insólito en formaciones neológicas, como son los derivados de anglicismos, de lo que dan muestra popez 'calidad de pop' y warez, del inglés ware, forma combinatoria utilizada a modo de sufijo en la designación de algunos instrumentos informáticos (ver software, hardware, etc.). Warez ([g]uaréz, [g]üearez) es un neologismo de raro uso empleado en telecomuniciacón con el significado de 'pirateo informático consistente en vender copias de CDs de manera ilegal' (GDA). 
-IA Sufijo infrecuente que da al derivado cierto sentido locativo y abstracto, tal y como observamos en la creación literaria Usaquia, con la que C.M. Ydígoras se refiere a la nación de los usacos 'sinónimo humorístico de 'norteamericanos' (ver Rodríguez González 1989: 236).

La terminación -ia, se observa también en serendipia, que expresa una cualidad y alterna con serendipidad, citada más arriba.

-NESs es un típico sufijo abstracto que en inglés se añade casi a cualquier adjetivo para formar nombres que expresan un estado o condición (kind $\rightarrow$ kindness, sweet $\rightarrow$ sweetness). Como anglicismo se encuentra solo en fitness y body-fitness 'gimnasia de mantenimiento', que ha entrado directamente en español, pues no se ha registrado el adjetivo fit 'en forma' en posición aislada.

\subsection{Sufijos adjetivales}

\subsection{1. de relación}

-(I)ANO Sufijo panrománico que expresa adherencia o relación, a menudo empleado con nombres propios de persona. Ya en latín lo encontramos ligado a los apellidos; cuando el nombre de persona terminaba en -ius, la terminación sufijal era -íanus (Valerius $\rightarrow$ Valeriano). Más adelante la secuencia -ianus se extendió a otros nombres y se convirtió en un verdadero sufijo (Victor $\rightarrow$ Victorianus). En español -iano es la forma que ha prevalecido, y de igual modo con anglicismos, tanto en derivados de nombres comunes (beselleriano < bestseller, carteliano ${ }^{20}<$ cártel, dragquiniano $<$ drag queen, grungeriano $<$ grunge, hardcoriano $<$ hard-core, jam-sessioniano $<$ jam-session, punkniano $<$ punk, westerniano $<$ western, como propios (Baconianon, Bowiano, Daltoniano, Disneyano, beatleliano). Con-ano tan solo he registrado usano 'norteamericano,

20 El segundo fue no haber detectado el perfil “carteliano" — que viene de cártel— de algunos de los dieciséis empresarios convocados, poco acorde con la finalidad del acto (Aurelio Alonso-Cortés, “Aznar y Blair en Downing Street”, Estrella Digital, 19-9-1981). 
habitante de USA', en uso humorístico y despectivo ${ }^{21}$, como variante de usiano.

En algunos derivados, como beatleliano y punkniano, se observa la inserción de una consonante /-l-/ y /-n-/, respectivamente, por diferentes razones. En el primer caso, como apoyo vocálico por razones de eufonía, pero propiciado también por el formato fonético [bítel] que contribuye a una mayor transparencia al preservar la forma léxica básica intacta; existe igualmente la forma beatliano, aunque es menos frecuente. En cuanto a punkniano, es una forma insólita, si se compara con la frecuencia de punkiano (Google registra 4 resultados de la primera variante tan solo y 317 de la segunda), innecesaria desde el punto de vista de la transparencia y la única base que posiblemente le avala es la asimilación consonántica con la $-n$, pese a la distancia en la articulación. También cabe observar el caso de otro derivado, grungeriano (< grunge $[r]$ + iano), donde la $-r$ - intervocálica también facilita una articulación más eufónica y natural.

-INO En español expresa relación, cualidad, origen (Numancia $\rightarrow-$ numantino, $\mathrm{ONU} \rightarrow$ onusino). El único derivado registrado con anglicismo es punkinino (en "música punkinina")22, empleado con un tono despectivo, quizá por asociación con los usos de voces españolas que expresan 'pequeñez', como chiquinino,-a 'chico muy pequeño', o 'cosa de reducida dimensión' y menino,-a 'niño $o$ adolescente de familia noble que entraba en palacio para servir a la reina').

-ICO Aunque frecuente para formar nombres diminutivos, en alternancia con los más usuales -ito e -illo, es menos fecundo como adjetival para denotar relación: aeróbico (< aerobics), bítico $(<$ bit), espídico (espid < speed 'anfetamínico'), lasérico ${ }^{23}$ (< láser), Spainico

21 Que se lo pregunten a Nixon. Claro que los “usanos” se lo hicieron pagar (José Cano Brustenga, "Las mentiras”, La Verdad, Albacete, 25-1-2008,Artículos Albacete).

22 No sé qué pasa, pero la música punkinina no cae muy bien (Gratix, n 5, verano 1985 , 19).

23 El País, 5-10-1986, 15. Citado en Rodríguez González (1989: 240). 
(< Spain), massmediatico (< mass media) y mediático (< media), quizá el más frecuente de todos ellos. A veces el sufijo se encuentra amalgamado a -ista, como en golfístico, jazzístico, padelístico, pedigrístico ${ }^{24}$, rockistico, rugbístico.

-Esco Sufijo adjetivo, reflejo del italiano -esco (que a su vez procede del latín -iscus), expresa, igualmente, pertenencia y relación ('a la manera de'), ver Pharies (2002). Suele emplearse en contextos despreciativos con el nombre primitivo al que aluden: beatlesco ( $<$ Beatles), cartoonesco (< cartoon), clownesco/clonesco (< clown), cowboyesco (< cowboy), balloweenesco (< Halloween), kukluxkanesco ( $<\mathrm{Ku}$ Klus Kan), mitinesco (< mitin < meeting), UFesco ${ }^{25}$ ( $<$ UFO 'ovni'), dandiesco $(<\text { dandy })^{26}$.

-oso De larga tradición en español, derivado del latín -osus, indica asimismo cualidad, relación o semejanza con el sustantivo del que parte como base léxica: espitoso y spitoso ('marchoso' < speed, espid), fanzineroso (<fanzine), hippyoso, hipioso (o jipioso) < hippie, bippy, piloso (< pill), serendipitoso (< serendipia, serendipidad), triposo 'relativo al trip'; 'consumidor de trips'. También significa 'que tiene, causa o abunda en: glamouroso/glamuroso < glamour), cruposo (< croup 'especie de laringitis').

-IL Sufijo adjetivo que indica relación o pertenencia y opera sobre bases sustantivas, como en gangsteril (< gangster). Es reflejo del sufijo latino -ìlis (Pharies 2002).

24 Fuera de estos restos de medicina primitiva característica de los estadios anmistas, el resto de la actividad terapéutica indicaba más bien una weltanschauung activistaempírica, propia de los pueblos cazadores y ganaderos y, en cuanto tal, muy educada al ambiente pedigrístico de la chabola (Martín Santos [1961] 1981, Tiempo de silencio, 132).

25 Sal Común, núm. 14 (“El enterao”). Citado en Rodríguez González (1989: 241).

26 En referencia a Francisco Rico, académico de la RAE:

[...] con la corbata azul tinta de nudo grueso y el dandiesco pañuelo de color amarillo imposible que se le derramaba desde el bolsillo superior de una chaqueta italiana de corte impecable (A. Pérez Reverte, Hombres buenos, Madrid: Alfaguara, 2015, 259). 


\subsubsection{Otros significados}

-OIDE Procedente del griego eĩosos [éidos] ('apariencia, forma'), el sufijo indica "semejante", tal y como lo ilustra el derivado funkoide $(<$ funk).

-ANTE Procede del latín -ans, -antis, desinencia flexiva del participio de presente activo de los verbos de la primera conjugación (Pharies 2002). Forma adjetivos para expresar 'quien ejecuta la acción' (amenazar $\rightarrow$ amenazante) y 'que tiene la capacidad de'; de ese modo se han creado los siguientes derivados: dopante $(<$ dopar), estresante (stress/estrés), flipante (<flipar) y tripante $(<$ trip), swingante, swingueante (< swing).

-ABLE Sufijo inglés que sirve para formar adjetivos a partir de cualquier verbo al que se añada, con el significado de 'capaz de o con posibilidad de'. Algunos derivados con anglicismos se han importado directamente del inglés, como wearable, de la jerga informática y electrónica, 'referido al aparato o dispositivos electrónico en miniatura que se incorpora en alguna parte de nuestro cuerpo...': lit. significa 'llevable, vestible' y resulta de la elipsis de wearable computer (ver $G D A$ ). El mismo sufijo muestra fashionable 'de última moda', muy frecuente hoy día al igual que la base fashion, originalmente relacionados con la moda en el vestir, pero hoy día aplicado a múltiples contextos: "negocios fashionables", "era muy fashionable", etc. El derivado fue documentado por primera vez en 1885, en la revista Blanco y Negro, y posteriormente, en 189, con la grafía fasionable (ver Fernández García 1972).

Igualmente merece citarse surfeable, que, a diferencia de los anteriores, se ha creado de forma autóctona a partir del verbo surfear, de frecuente uso, y no por préstamo directo del inglés surfable, cuya morfología y fonética difiere notablemente del español, y amalgamado al sufijo-izar, containerizable y customizable,

-EIBOL En realidad es una forma adaptada de la anterior basada en la grafía fonética y empleada en el lenguaje oral de modo exclusivamente humorístico. Es un uso macarrónico consistente en sustituir la terminación -íble y-able de voces patrimoniales por el sufijo -able 
pronunciado a la inglesa: conforteibol (por confortable), imprescindeibol (por imprescindible), incredibol o increibol (por increible), lamenteibol (por lamentable).

\subsection{Sufijos adverbiales}

-MENTE es sufijo adverbial que virtualmente puede adherirse en español a un adjetivo de cualquier terminación, pero preferentemente si la base léxica termina en vocal (claro $\rightarrow$ claramente, torpe $\rightarrow$ torpemente). Con anglicismos esta derivación adverbial es rara, pero el modelo se pone en práctica con windsurfístico $\rightarrow$ windsurfísticamente. Insólita, sin embargo, es la afijación con esnob $\rightarrow$ esnobmente.

\subsection{Sufijos verbales}

Los derivados verbales son obtenidos a partir de una base léxica nominal y responden a dos tipos principales: a) derivados sin sufijo, con la simple transcategorización mediante la desinencia verbal y que en español actual se ve reducida a la flexión de la primera conjugación en -ar (ocasión $\rightarrow$ ocasionar) y b) derivados con sufijo, -ear e -izar, ambos con origen en la terminación verbal griega -í̧єıv, transcrita en latín popular como -idiare. Este doble tipo de sufijación recibe los nombres de "derivación inmediata” y "mediata”, respectivamente (Menéndez Pidal 1977: 325).

La primera (en -ar) es menos frecuente, y menos aún con los anglicismos, pero aun así el GDA registra un buen número de voces (34):

clampar, claxonar, displayar, driblar, dropar, empichar, esmasar esmoquingar, esprintar, snifar/esnifar, estresar, fanfictionar, filmar, flipar, googlear/guglear, handicapar, impeachmentar, impichar, interviewar/interviuar/interviuvar, liderar, liftar, linchar, linkar, microfilmar, ninfar(se), pudelar, shuntar, sprintar/esprintar, ponsorar, stockar, testar, topar, tripar, trolar, zapar ${ }^{27}$.

\footnotetext{
27 Un reciente neologismo es selfiar (< selfi + -ar) 'hacer un selfie': "Pero hace justo un mes que ni salen ni selfían juntos” (F. Jiménez Losantos, "Las cuatro esquinas”, El Mundo, La Otra Crónica,10-10-2020, 19).
} 
A la derivación "mediata" responden dos sufijos verdaderamente productivos en las lenguas románicas, -ear, que designa una imitación como en blanco $\rightarrow$ blanquear, y que más tarde dio lugar a la forma culta -iz-ar, como en latin $\rightarrow$ latinizar). Los dos se repiten en los derivados con anglicismos. Aunque en rigor los derivados verbales constituyen en sí innovaciones de carácter culto, de algún modo pueden diferenciarse dos niveles lingüísticos en relación con el sufijo empleado:

a) -EAR tiene lugar en derivados de uso más coloquial, y entre ellos los humorísticos, por lo que son más numerosos. En el $G D A$ y el $D A D$ he espigado los 82 siguientes:

autostopear, backapear/backupear, banear, batear, beepear, birdear, bisnear, bloguear, blufear, boxear, canicrossear, chartear, chatear, chipear, clickear/cliquear, craquear, deletear, dilear, draftear, draivear driblear, escanear, espoilear, faxear, fildear, fishear, fistear, flashear/flasear, flirtear, freakear, futbolear, wasapear/guasapear, gayear, golear, googlear, jabear hackear, buliganear, hypear, jabear, impiechar, knoquear/noquear, latear, leakear, mitinear, mopear, nocautear, noquear, patear, photoshopear, pichear/pitchear, playbaquear, plotear, postear, punkear, puttear, rapear, remakear, renamear, resetear, ridear, rostear, rocanrolear, runnear, samplear, scratchear, shapear, sortear, spamear, spoilear, stalkear, stockear, surfear, swingear, tagear/taquear, twistear, twittear/tuitear, tripear, trolar, tunear, windsurfear, zapear/zappear/zapinear.

Aparte cabe mencionar también funkear ${ }^{28}\left(<\right.$ funk), lobbytear ${ }^{29}$ ('hacer lobby'), whisquear ${ }^{30}$ ('consumir whisky').

\footnotetext{
28 Es hora de funkear con una banda de criminales sonores. Abran paso a The Free Association. Sus inminentes shows en Madrid, Bilbao y Barcelona se anuncian incendiarios (Shangay, 24-3-2003).

29 Recordemos que mientras, [Xavier Cima, marido de Inés Arrimadas] sigue lobbyteando en la consultora Kreab (Emilia Landaluce, El Mundo, La Otra Crónica, 2-11-2019, 20).

30 Nos sorprendió a Pedro Mario Herrero, corresponsal volante del Ya, y a mí cuando whiskeábamos al buen tuntún: el ABC le enviaba a Arenas con el mismo objeto (Pardo 2001: 213).
} 
Para una descripción más amplia de estos derivados, sobre todo en el español de América, así como de los procesos morfofonológicos que atraviesan en su adaptación, ver Yoza (2013).

Virtualmente, a partir de estos verbos se pueden crear los correspondientes sustantivos que denotan la 'acción', mediante el sufijo -EO: ${ }^{31}$

bisneo, boxeo, chateo, cliqueo, craqueo, dileo, dribleo, escaneo, faxeo, hackeo, mitineo, pitcheo, ploteo, popeo, sampleo, tuneo, twuitteo, zapeo/zapinneo.

Y el efecto, mediante el sufijo -ADO:

baneado, escaneado, sampleado

b) -IZAR lo encontramos con menos derivados, normalmente en crónicas periodísticas que hacen uso de un tono más elevado, como en los 21 siguientes incluidos en el GDA:

bowdlerizar, chopperizar, coctelizar, computerizar, containerizar, customizar, gangsterizar, glamourizar, macadamizar, masterizar, mercerizar, mesmerizar, oscarizar, parkerizar, presurizar, queerizar, randomizar, remasterizar, roastizar, sanforizar, sponsorizarl esponsorizar.

Virtualmente a partir de estos verbos se pueden crear sustantivos, mediante el sufijo-AcIóN:

bowdlerización, computerización, customización, esponsorización, masterización, queerización

-FICAR Similar semánticamente a -izar es -ficar 'transformarse en X' registrado con el anglicismo campificar 'convertir en 'camp' (y su derivado nominal campificación). Neologismo reciente más usual es gentrificar (y gentrificación), alusivo a la idea de 'convertir un barrio depauperado de una gran ciudad en otro de mejor aspecto

31 En spaseo 'utilización de los servicios de un spa' no se ha documentado el verbo de apoyo, y probablemente se ha creado por analogía con paseo. Lo mismo ocurre con flopeo 'acción de pintar graffiti con una línea rápida' probablemente derivado del verbo inglés to flop' no documentado en el corpus. 
debido a la entrada de habitantes con gran poder adquisitivo'. Son formaciones de carácter culto en las que pocos adivinarán la base que encierra su morfología, gentry 'en Inglaterra clase constituida por la pequeña nobleza, con derecho a blasón pero sin título nobiliario'. Otro uso reciente es trumpificarse, utilizado por el escritor Javier Marías para referirse al comportamiento de su homólogo Boris Johnson en Gran Bretaña ${ }^{32}$.

La segunda conjugación del verbo no está representada salvo con el sufijo "incoativo" -ECER, empleado para denotar una transformación o cambio de estado: enrockecer, enwhisquecer, ilustrado mediante las formas parasintéticas y participiales enrockecido/ enrokecido y enwhiskecido ${ }^{33}$.

\section{VARIACIONES DE LA SUFIJACIÓN DERIVATIVA: ASPECTOS MORFOFONOLÓGICOS, ESTILÍSTICOS Y SEMÁNTICOS}

Al hablar de las distintas formas de los derivados, se habrá observado la existencia de diversas variantes de orden morfofonológico (flashear/flasear, hippyoso/hippioso/jipioso, spitoso/espitoso; spidico/ espídico, wasapear/guasapaear. Este doblamiento de tipo formal, que afecta al anglicismo en tanto que lexema base del derivado, forma parte de un fenómeno más general conocido con el nombre de "morfovariación" (Natanson 1976), al que se considera normal y propio de las lenguas más desarrolladas. Porque es un proceso normal en el léxico no puede ser condenado, aunque siempre es previsible y deseable que se produzca una simplificación de formas, como si se tratara de una selección natural. Pero en el periodo de transición hasta que el uso queda del todo consolidado y establecido, la elección de una u otra variante (con o sin escritura fonética,

\footnotetext{
32 Ese país astuto [Gran Bretaña], astuto, pragmático, civilizado, encumbró a Boris Johnson, cuando este se "trumpificó", empezó a comportarse como un chulo majadero, a hablar como un fan toche y a prometer con malos modos a su nación a la ruina (Javier Marías, "Buenísimas personas”, El País Semanal, 10-11-2019, p. 90).

33 Los camareros del Roma habían asimilado la campechanía acampanada y enwhiskecida de sus habituales, tanto patricios como aspirantes al patriciado [...] (Pardo 2001: 73).
} 
en los ejemplos citados) varía de acuerdo con la actitud — conservadora o rupturista - del hablante o escritor hacia la norma escrita y el tipo de género periodístico en que se encuadra el texto en cuestión.

En los derivados las variaciones o fluctuaciones son más frecuentes que en otras categorías y se dan especialmente en formaciones con carácter nominal y adjetival. En cuanto a la derivación nominal, la variación más llamativa tiene lugar en derivados que designan conceptos con una referencia personal, y existe en la medida en que existen distintos "sufijos de caracterización": $\varnothing,-y$, er $(o)$. Los dos primeros son de uso inglés, mientras que el segundo (especialmente el “alomorfo" -ero) es creación autóctona -y “anisomórfica”, en la terminología de Pratt (1980). Los ejemplos son abundantes en el argot de las subculturas juveniles, especialmente en el campo de la música.

-Ø: heavy metals (o metalpesados), folks, punks, freaks.

-y: yippy, yuppy, punky, yonqui, bluesy, poppy, drogui (del inglés druggy).

-er/ero: rocker/rockero, bluesero, punkero, hiphopero, raver/ravero y también el calco nuevaolero.

Por su frecuencia y grado de aclimatación, los dos últimos son los patrones más importantes. Sin duda alguna han sido bippy y rockero, respectivamente, las "palabras líder" que han actuado como modelo analógico ${ }^{34}$, dada la resonancia de estas subculturas y estilo musical entre los jóvenes.

Con algunas voces hay un forcejeo entre dos o tres patrones derivacionales, entre el modelo inglés y español (e.g. blusie/bluesero $^{35}$ ); freak/freaky (freakado); punks/punkies punkeros.

En la derivación adjetival existe, igualmente, un reciente y singular caso de fluctuación: grunge / grungy. La primera variante

34 Empleo este término siguiendo a Malkiel (1950-1: 17) que llama "leader word" ('palabra dominante o líder'), a una palabra que actúa como modelo analógico para acuñaciones similares.

35 Recomendado para todo tipo tipo de públicos, desde los aficionados al tango hasta los más puristas blueseros (Vivir [Alicante], oct. 1992, 14). 
está más en línea con el uso en inglés, la segunda muy probablemente se ha creado por analogía con funky, punky, yuppy, etc. El siguiente fragmento contiene las dos formas:

“Seattle, no faltaba más, es muy grunge”... vestimenta grunge...estética grunge... vs. "con unas notas de angostura agridulce y un toque grungy ... un músico que toca en grupo grungy" (Woman, junio 1993, 80).

También cabe mencionar la singular variación entre -oso e ico que se ha establecido con el término speed: espídico ('anfetamínico'), espitoso ('marchoso'). La variación no es casual porque viene dada por la analogía con los sinónimos (o parasinónimos) que les han servido de modelo.

En la derivación verbal y postverbal existe un llamativo e interesante caso de variación morfológica: zapar, zapear, zapinear, análoga a la de los nominales postverbales zapping y zapeo. La primera de ellas, un tanto infrecuente, es la más humorística, en tanto que evoca con mayor claridad una motivación onomatopéyica; la segunda es la más establecida, y, junto con el correspondiente sustantivo postverbal, zapeo, ha sido propuesta desde las tribunas periodísticas por algunos hombres de letras; la tercera, de la que he encontrado tan solo dos citas, busca una transparencia semántica apoyándose en la evocación del nombre zapping. De todos modos, lo más frecuente es utilizar el híbrido "hacer zapping”, y todavía más, la construcción española "cambiar de canal”.

La variación -ar/-ear aparece también con otros anglicismos; driblar/driblear, liderar/liderear, siendo estas últimas variantes en - ear más frecuentes en variedades del español de América, como México. En el caso de lobbytear, mencionada antes, la /-t-/ intervocálica sirve de apoyo para evitar la secuencia cacofónica de dos vocales seguidas y probablemente se debe a la analogía con derivados como como bailotear (< baile).

Parecido proceso de variación morfológica, y por parecidas motivaciones, tiene lugar en anglicismos sustantivos cuando se convierten en lexema base de la derivación. E.g. glamour $\rightarrow$ 
glamouroso, glamuroso; hippy $\rightarrow$ hippyoso, hipioso (jipioso), y el ya citado de speed $\rightarrow$ spitoso, espitoso; $\rightarrow$ speedico, espídico. Los dobletes se detectan también en algunos derivados eponímicos; por ejemplo, de Sporting, nombre de un equipo de Primera División español, se han formado sportinguista y esportinguista, y de Chomsky, conocido lingüista, chomskiano, chomsquiano y chomskyano. El fenómeno es familiar en español, pues se presenta con llamativa frecuencia en los derivados de apellidos de personajes extranjeros: Stalin $\rightarrow$ stalinista, estalinista; Trotsky $\rightarrow$ trotskyista, trotsquista, trotskista. El doble procedimiento seguido en estas formaciones, dejando intacto o alterando el lexema base, está íntimamente relacionado con el deseo de dar transparencia o no al significante extranjero.

Como en el caso de Trostky, con los anglicismos terminados en $-y$, como funky, hippy, punky, lobby, el escritor se enfrenta al dilema de dejar intacta la base o radical o convertirla en $-i$ antes de añadir un sufijo, lo que explica las distintas posiciones encontradas: hippyoso vs. hippiuelo, hippirulo; punky vs. punkirulo; lobby, lobbysmo, lobbysta, lobbytear, lobbying vs. lobbism o, lobismo, lobbista, lobista.

En principio no parece muy conveniente, estimo, escribir en redonda, es decir, sin cursiva, formas tan poco acordes con la escritura fonética del español como glamouroso [glamuroso] y bluesero [blusero], pero, por otro lado, la dualidad de grafías revela una toma de posición — de tolerancia - frente al fenómeno de la transparencia, que también tiene sus condicionamientos. Al examinar el adjetivo glamouroso/glamuroso, observamos que con frecuencia las dos formas alternan en la escritura, al compás de las formas nominales base de la derivación glamour/glamur, sin que el sentido quede oscurecido. Frente a estas vacilaciones, no es por casualidad que bluesero contraste en frecuencia con blusero, apenas registrado, que podría llevar al lector a una fácil asociación con blusa. Esto quiere decir que el riesgo de ambigüedad podría bloquear una determinada adaptación gráfica. 
El fenómeno de la "ramificación" de derivados con sufijos diversos, o sea, la multiplicidad de sufijos adosados a un mismo anglicismo es muy frecuente. Aparte de los mencionados, se pueden añadir bestselleriano/bestsellerista/bestsellero; clubistal clubero/clubman; windsurfista/windsurfero/windsurfeta. Este tipo de "morfovariación derivativa" viene determinada por un doble o triple sufijo cuya morfología no es casual. Constituye un tipo de variación inevitable, pues se apoya en el deseo del hablante o escritor de procurarse de variados contenidos semánticos, denotativos y connotativos con los que atender a sus necesidades estilísticas y comunicativas, de manera que el empleo de sufijos en los anglicismos depende, en último término, del arbitrio del usuario, quien puede mostrar preferencias por una forma determinada. Aunque el uso común termina seleccionando un sufijo específico en ciertas caracterizaciones, al menos con los anglicismos más frecuentes, a veces se encuentran textos donde el escritor movido por pretensiones estilísticas, utiliza variantes morfológicas muy marcadas: por ejemplo, -ata, -eta, -arra para adecuarse a un contexto marginal o juvenil, -ero para un uso popular o familiar, o -ista para otro más neutro, u oficial.

Parecida función cabría postularse en casos de "morfovariación derivativa" en los que aparece un doble sufijo (español e inglés) a partir de una misma base inglesa (rock). Así, rocker y rockero (o roquero), dos formas derivadas mediante un mismo sufijo de agente "personal", mantienen una pequeña y sutil diferencia de sentido, pero solo en español, pues el inglés registra un solo derivado (rocker). En español roquero 'relativo a, o practicante del rock' es una creación anisomórfica, según la terminología de Pratt (1980: 158), ya que cumple la función adjetival asignada en inglés al nombre rock, que de esta forma es ambivalente (rock [n] y rock music [adj.]), además de compartir algunos de los usos del inglés rocker. Sin embargo, frente al significado general de rockero (o roquero), rocker (y su pl. rockers) en español tiene un significado más específico, designando al 'cantante de rock', pero también a un 'miembro de un movimiento juvenil o tribu urbana, de carácter 
bastante agresivo e ideología contracultural, que tiene al rock como principal símbolo de identidad'. Ambos significados están presentes en las dos frases siguientes, aunque, como se observará, solo en la primera de ellas rocker podría sustituirse por roquero.

Townshend acusaba claramente a su colega de 40 años de ser demasiado viejo para seguir siendo un rocker (El País Semanal, 10-2-1985, 7).

A veces los rockers entran al asalto en Cristiania y la policía vigila las estampidas detrás de la empalizada sin levantar una ceja (El País Semanal, 20-5-1984, 27).

Alguna vez la diferenciación puede ser tan sutil como en el par explorer/explorador. Explorador es la traducción del inglés scout y designa a los pertenecientes al Movimiento Escultista Español, utilizado todavía en los nombres de algunas asociaciones scouts. En el DEA (Diccionario del español actual) lleva la marca de 'raro'. Por el contrario, explorer (abreviación de explorer scout) en algunas asociaciones indica al scout de una determinada edad, de más de 15 años según Hernández Roselló (1999).

Para terminar el cuadro de la variación léxica en los derivados de anglicismos, me referiré al variable semantismo de algunos de ellos. Al margen del significado ordinario que le corresponde por su sufijo, en ocasiones el derivado desarrolla nuevas significaciones mediante proceso de "extensión” o "restricción”, o por transposiciones semánticas de tipo metonímico o metafórico. Así, la diferencia de significado aparece clara en el par chopper/choppero, ambos con sufijo con valor de agente, pero donde es radical la oposición “-animado" / "+animado” que distingue a sus clasemas. Chopper es el objeto inanimado, y designa un tipo de moto y bicicleta, mientras que choppero (o chopero) designa al conductor de estas motos o bicicletas, de manera que el cambio de morfema sufijal, -er vs. -ero, en este caso se ve acompañado de un deslizamiento metonímico.

La diferencia se hace igualmente ostensible cuando el significado de derivado entra en una especialización que varía según el contexto o campo léxico al que pertenece y donde entran en juego 
la transposición metafórica. Así, scouter, designa al jefe de una sección de scouts, pero en un uso más general significa la 'persona dedicada al scouting', esto es, a la 'búsqueda de talentos en distintas áreas, especialmente el deporte, o de personas con buena figura para trabajar como modelos', lo que se conoce también como ojeador.

El empleo de la metáfora con fines estilísticos es aún más frecuente en las formaciones verbales. Ejemplo palmario lo presenta flashear, que del significado argótico que tiene en la jerga de la drogadicción 'bombear sangre con la jeringuilla para aumentar la sensación producida por la solución inyectada' ha pasado a usos figurados como 'sorprender, maravillar' y 'ornamentar' (ver GDA). Cambios análogos se produjeron con flipar (ver Rodríguez González 1994).

Finalmente. en lo tocante a estilo. cabe mencionar el variable marco sintáctico en cuanto al recurso léxico-formativo elegido según la preferencia del usuario de la lengua, especialmente escritor, que puede optar al referirse a una acción verbal por una esquema compositivo (hacer zapping) o derivacional (zapear, zapinear) y al cualificar a un referente de modo adjetival por un patrón analítico (por ejemplo, "lenguaje de internet", que sería el estándar y más usual) o por uno sintético y más expresivo, a menudo remarcado diacríticamente con la cursiva, mediante un derivado, "lenguaje internetero" 36 .

\section{Tratamiento lexicográfico de las FORMAS DERIVADAS}

Los repertorios lexicográficos que se ocupan de los anglicismos, ya sean tratados monográficamente o integrados como parte de diccionarios de extranjerismos o neologismos, por lo general, raras veces incluyen en sus entradas formas derivadas, y esto por razones de espacio al estimar que son formas semánticamente transparentes cuyos significados son fácilmente deducibles. Aunque de manera asistemática, por el carácter neológico de los derivados, Del Hoyo (2002), autor de uno de los más solventes y meritorios diccionarios

\footnotetext{
36 "Un deseo que traducido al lenguaje internetero de sus escritos podría resumirse como «Ojalá todo funcionara tan bien como Gmail»" (S Moda, [Suplemento de moda de El País] n² 257, enero 2020, p.135).
} 
de voces extranjeras, recoge un buen número de voces así formadas como biker, bisnero, glamouroso, sprinter/sprinter. Por su parte, el $G D A$, que ha servido de fuente para este estudio, guiado por un criterio sumamente descriptivo y práctico, al conformar la microestructura ha dado entrada a numerosísimos neologismos, así como a sus correspondientes variaciones fonológicas y morfológicas, como el anterior apartado y el siguiente apéndice deja patente.

En primer lugar, y de manera general, se han considerado los derivados de cada base léxica con sus distintas funciones gramaticales, como por ejemplo, de <funk $>$ : tanto los nombres funkero, funkman, funkwoman, como los adjetivos funkoide, funky, pero también se han señalado sus diferentes valores semánticos cuando procede, por ejemplo, de $\langle f u n k y>$, el $a d j$. y $n$. referido a la música como acepción básica, pero también el sustantivo referido a un 'tipo de danza callejera' bailada al ritmo de la música del mismo nombre, y el adj y $n$ empleado en el contexto de la vestimenta y la moda en referencia a la 'moda extravagante caracterizada por el uso de prendas de sport, colores caribeños, cuadros, rayas, gorras, colgantes étnicos, etc.' Asimismo, cuando la pronunciación y la grafía es variable por razones sociolingüísticas, en función de los diferentes niveles de instrucción y extracción social de sus hablantes, se han lematizado sus correspondientes dobletes, en este caso funky/ funki y fanky/fanqui. Igualmente, con determinados derivados, a estos factores se han añadido el registro, desp 'despectivo', como en yonkarra y yonquirulo, bum 'humorístico', como en lideresa y yupillaje, y la marca infrec, como con yonquie y junkismo, todos ellos derivados de la formas inadaptadas inglesas junk 'heroína' y junkie 'heroinómano'.

Cuando la "familia léxica" creada en torno a una base léxica es muy larga, por ejemplo con la entrada < fútbol>, al final del artículo se han listado todos los derivados con un carácter exhaustivo y en negrita:

DERIV: fulbito, futbito, futbolear, futbolería, futbolero, futbolín, futbolismo, futbolista, futbolístico, futbolistas, futbol(o)manía 
Aunque posteriormente se han aislado y dado entrada diferente a los diminutivos futbito y futbolín, debido a sus significados tan específicos, omitiendo las demás voces por ser más deducibles.

\section{Conclusión}

El notable aumento de derivados con anglicismos corre en paralelo con la creciente influencia de los préstamos que les sirven de base. La derivación conlleva una mutación funcional por la cual el anglicismo, normalmente nominal, se transforma en verbo, adjetivo, o bien otro sustantivo. De entre los derivados, destacan por su frecuencia léxica y de utilización aquellos referidos a la caracterización personal (frecuentemente de tipo agencial o agentivo) y en torno a variados conceptos expresados por el lexema base (función nominal), o bien los que sirven para cualificar algún referente relacionado con los mismos (función adjetival). Virtualmente los sufijos pueden unirse a cualquier lexema foráneo, pero en la práctica esto principalmente ocurre con los de uso muy frecuente, lo que otorga al sufijo utilizado un alto grado de "disponibilidad".

Los derivados, en general, son acuñados y empleados en la lengua escrita, sobre todo dentro del ámbito periodístico, aunque no faltan algunos cuyo extendido uso invade los dominios del lenguaje oral (roquero, rapero, flipar, yonqui). Los textos en que aparecen se caracterizan por un estilo formal, si bien algunos, por su especial contextura (rocker, skinorro, flipeta), añaden connotaciones afectivas - positivas o negativas-y/o humorísticas que de este modo alimentan aún más las pretensiones estilísticas del usuario. No faltan tampoco creaciones léxicas con carácter de argot que tienen su origen en la lengua hablada dentro de sectores muy especiales (jergas), desde donde son recogidas por el periodista, quien a su vez los catapulta a través de los media, lo cual produce una especie de ósmosis recíproca.

Los sufijos más propensos a ser objeto de préstamo y analogía morfológica son los considerados "cognados" y funcionalmente relacionados, como -er/-ero, -ist/-ista, -ism/ismo, lo que contribuye a su más rápida integración en la lengua (ver Matras 2014: 
48). En estos casos el derivado español tiende a prescindir de marca tipográfica, salvo que por su carácter de argot y su motivación expresiva se desee destacar en cursiva.

Las posibilidades léxicas del derivado adquieren una nueva dimensión cuando se contemplan procesos semánticos más complejos, tales como la restricción, la extensión o metaforización de sus significados. A pesar del rico y variopinto caudal de formas que acompañan a los derivados con anglicismos, la formación y uso de estos obedecen a reglas fonológicas, morfológicas y semánticas muy precisas, análogas a las seguidas por otras voces de la lengua. El carácter minúsculo del que se recubren usualmente, reforzado tipográficamente mediante el uso de la redonda, les da una fisonomía léxica normal, fiel exponente del grado de lexicalización alcanzado por el préstamo en cuestión y en virtud del cual el lexema derivativo puede considerarse como una verdadera y nueva unidad léxica de la lengua.

Aunque los derivados con anglicismos afectan fundamentalmente a la categoría del nombre y adjetivo, el corpus manejado para este estudio ha puesto de manifiesto la creciente frecuencia de los derivados verbales — como se resalta en el Apéndice-, tanto en lo que atañe a su "frecuencia léxica", considerando el conjunto de todas sus formas, como a la "frecuencia de uso" de algunas unidades en particular. De cualquier modo, ambos parámetros son un buen índice del arraigo de los anglicismos que les han servido de base.

\section{REFERENCIAS BIBLIOGRÁFICAS}

Colin, Jean-Paul y Jean-Pierre Mével

1990 Dictionnaire de l'argot. París: Larousse.

Coll, Alba

2007 "El sufijo -ing ¿creatividad al poder?”. Donde dice... (Boletín de la Fundación del Español Urgente). 9, 16.

CONTRERAs, Heles

1972 “Una clasificación morfosintáctica de las lenguas románicas». En Readings in Romance Linguistics. Eds., J.A. Anderson y Jo Ann Creore. La Haya: Mouton, 101108. 
Del Hoyo, Arturo

2002 Diccionario de palabras y frases extranjeras. $3^{a}$ ed. corregida y aumentada. Madrid: Santillana.

Fernández García, Antonio1

1972 Anglicismos en el español. (1890-1936). Oviedo: Gráficas Lux.

FERNÁNDEZ, Lluís

1992 Espejo de amor y lujo. Barcelona: Laertes.

GonZÁLez García, Luis

2019 "Formación de palabras en español actual". En Lengua, cultura, discurso. Estudios ofrecidos al profesor Manuel Casado Velarde. Eds., Ramón González Ruiz, Inés Olza y Óscar Loureda. Pamplona: Ediciones Universidad de Navarra (EUNSA), 631-652.

GonZÁlez Ollé, Fernando

1962 Los sufijos diminutivos en castellano medieval. Madrid: CSIC.

Grijelmo, Álex

2019 Propuesta de acuerdo sobre el lenguaje inclusivo. Madrid: Taurus.

HeRnández Roselló, Julio

[1970] 1999 Diccionario scout. Sexta edición, corregida y aumentada. Cartagena, Murcia: CE.CO.IN.ES.

LANG, Mervyn, F.

1992 Formación de palabras en español. Madrid: Cátedra.

LEÓN, Víctor

1980 Diccionario de argot español y lenguaje popular. Madrid: Alianza Editorial.

Malkiel, Yakov

1950-51 "The Latin Backround of the Spanish Suffix -uno". Romance Philology. 4, 17-45.

MALKIEL, Yakov

1958 "Los interfijos hispánicos (Problema de lingüística histórica y estructural)". En Estructuralismo e historia. Miscelánea-homenaje a Martinet. II. La Laguna: Universidad de La Laguna, 107-199. 
Martínez Celdrán, Eugenio

1978 "Los conceptos de interfijo e infijo en español". Revista Española de Lingüística. 8, 2, 447-460.

MATRAS, Yaron

2014 "Why is the Borrowing of Inflectional Morphology Dispreferred?”. En Borrowed Morphology. Eds., Francesco Gardani, Peter Arkadiev y Nino Amiridze. Berlín: De Gruyter Mouton, 47-77.

MenËndez Pidal, Ramón

1977 Manual de gramática histórica española. Decimoquinta edición. Madrid: Espasa Calpe.

Motт, Brian

2015 "The Rise of the English -ing Form in Modern Spanish: A Source of Pseudo- Anglicisms". En Pseudo-English: Studies on False Anglicisms in Europe. Eds., Cristiano Furiassi y Henrik Gottlieb. Berlín: De Gruyter Mouton, 175-196.

NATANSON, Edouard

1976 "Morphovariation et ramification des termes". Lebende Sprachen. 21, 13-16.

PARdo, Jesús

2001 Memorias de memoria. Barcelona: Anagrama.

Pharies, David

2002 Diccionario etimológico de los sufijos españoles. Madrid: Gredos. Picone, Michael D.

1996 Anglicisms. Neologisms and Dynamic French. Ámsterdam / Filadelfia: John Benjamins.

PratT, Chris

1980 El anglicismo en el español peninsular contemporáneo. Madrid: Gredos.

RAMONCÍN

1993 El tocho cheli (Diccionario de jergas, germanias y jeringonzas). Madrid: Temas de Hoy.

Rodríguez GonZÁlez, Félix

1988 "The Proliferation and Use of Acronym Derivatives: Conditioning Factors”. Cabiers de lexicologie. 52, 1, 111126. 
RodríGUEZ GONZÁLEZ, Félix

1989 "La derivación de las siglas". Boletín de la Real Academia Española. 69, 247, 211255.

RODRíGUEZ GONZÁLEZ, Félix

1994 "Remarques sur les glissements de sens dans l'argot. A propos du langage de la drogue et les anglicismes en espagnol". Cabiers de Lexicologie. 64, 1, 147-154.

RODRíGUEZ GonZÁLEZ, Félix

1995 "Spanish influence on English word-formation. The suffix -ista". American Speech. 70, 4, 421-429.

Rodríguez GonZÁlez, Félix

1996 Spanish loanwords in the English Language. Berlín-Nueva York: Mouton de Gruyter.

Rodríguez GonZÁlez, Félix

2013 "Pseudoanglicismos en español actual. Revisión crítica y tratamiento lexicográfico". Revista Española de Lingüística. 43, 1, 123-169.

Rodríguez GonZÁLEZ, Félix

2017a Gran diccionario de anglicismos. Madrid: Arco/Libros.

RodríGuEz GONZÁLEZ, Félix

2017b "El plural de los anglicismos: panorama y revisión crítica". Boletín de la Real Academia Española. Cuaderno 315, 297-327.

RodrígueZ GonZÁLEZ, Félix

2020a "Un nuevo sufijo en español: -er". ArchiLetras. 9 (octubre diciembre), 112-113.

Rodríguez GonZÁlez, Félix

2020b "Anglicismos y formaciones compuestas en español actual". Lingüistica Española Actual (en prensa).

Rodríguez GonzÁlez, Félix, y Jesús CASTAÑón Rodríguez

2021 Diccionario de anglicismos del deporte. Madrid: Arco/Libros.

Roig-Marín, Amanda

2016 "Anglicisms in music fandom terminology: The idiosyncratic use of self-referential nouns in the language of youth. Atlantis. 38, 2, 181-199. 
Roig-Marín, Amanda

2017 "Contextualizing the emergence of English induced morphological borrowing in Spanish: The case of -er". Spanish in Context. 14, 3, 391-412.

SeCo, Manuel y otros

2011 Diccionario del español actual. Segunda edición actualizada. Madrid: Aguilar.

Selva, Juan

1949 "Sufijos americanos". Thesaurus. Tomo 5. Números 1, 2 y 3, 192-213.

Tekavčić, Pavao

1972 Grammatica storica dell'itliano. Il Mulino, volumen 3. Bolonia: Lessico.

Vigara Tauste, Ana María

1999 “Cañóning”. Espéculo (El cajetín de la lengua). Madrid, 30 de agosto de 1999.

YDigoras , Carlos María

1967 Los usacos. Madrid: Arrayán.

YozA, Natalia

2013 "Préstamos de ítemes léxicos del inglés al castellano: formación de neologismos en -ear". Tesis de licenciatura. Pontificia Universidad Católica del Perú.

Zacarías Ponce de LeÓn, Ramón F.

2016 "Análisis morfológico, semántico y lexicográfico del sufijo -erío en el español de México”. Thesaurus. 58, 30-52.

ZANDVOORT, R.W.

[1957] 1972 A Handbook of English Grammar. Londres: Longman. 


\section{APÉNDICE}

Entradas registradas en el $G D A$ y en el $D A D$ con los sufijos más representativos

\section{SufiJOS DE AGENTE:}

$$
\text { -er }[=313]
$$

aquarunner. baby blogger, backer, banner, back-bencher, backhander, barter, bartender, baby boomer, baby-sitter, bearchaser, beatboxer, beeper, best-seller, biker, bitter, blaster, blazer, blister, blackandecker, blogger, boarder, body boarder, body-builder, bomber, booker, bookmaker, boomer, booster, boper, boulder, breakdancer, breaker, bloomer, boarder, body-packer, body-stuffer, bouncer, bowler, boystripper, broker, browser, buffer, bulldozer, bunker, camper, caster, catcher, center, centerfielder, challenger, charter, chaser, cheer leader, chequera (f.), chipper, chopper/choper), clinker, clipper, clubber, cocker, cocooner, colider, commuter, container, controller, cooler, cooper cosplayer, counter cover, cracker, croner, crooner, cutter, dealer, destroyer, diner, docker, downer, downshifter, dragster, driver, duffer, dumper, duster, eggbeater, entertainer, erothriller, espiquer/speaker, estriper/stripper, eyeliner, fader, filler, filder, filter, flanker, flapper, flatlander, flex player, flipper, floater, fluffer, flutter, flyer, folk-singer, 49er, free lancer, free rider, freestyler, fun boarder, gamer, gayer, glitter, goal keeper, gunner, hacker, hammer, handicapper, handler, hard-bopper, hater, headbunter, highlander, hilander, hip-hopper, hipster, hooker, hopper, bunter, jetsetter, jacker, jaker, jogger kicker, kick-starter, killer, klicker, klister, knuckler, leader/lider, leftfielder linebacker, liner, linker, lipliner, lofter, looser/loser/lúser, lover (en latin lover), manager, marker, master, matchmaker, match player, medical-extender, merchandiser, microblogger, miller, montgolfier, moonlighter, motorsailer, moto stayer, musher, mystery shopper, newcomer, nightclubber, off-roader, on deck batter, one-liner, one tonner, outer, outfielder, outliner, outrigger, outside center, outsider, oxer, pacemaker, partner, personal shopper, personal trainer, pitcher, playbacker, player, pointer, poker, plotter, popper, prompter, puller, punk-rocker, puscher/pucher/ puser, putter, raider, ranger, raper/rapper, psychokiller, psychothriller, 
puncher, putter, quaker, quarter-back, quarter court, quarter pipe, quencher, quiver, raver, reporter, retriever, rider, ripper, roadmanager, rocanroller, rocker, roller, rollerskater, router, rover, runner, sampler, sand blaster, sandwicheralsangüichera, scanner, schwinger, scooter, scorer scouter, scraper, scrubber, setter, shaper short seller, shooter, skateboarder, skater, skier-X, skimmer, skinner, skipper, sleeper, sleepers, slider, slow roller, snakeboarder, sneakers, sniffer, snooker, snowboarder, soccer, spammer, spanker, speaker, speechwriter, spider, spinnaker, spinner, spoiler, spotter, sprinter, stripteaser, squatter, stakeholder, starter, stayer, steady-seller, stepper, stopper, streaker, streamer, striker, stripper, supporter, surfer, swagger, sweeper, swinger, swinguer, tagger, teenager, telemarker, teleprinter, teleprompter, tester, thriller, toaster, toner, toplessera (f.), top-scorer tourer, trader, trailer, trainer, trawler, trekker/treker, trendsetter, tripper, trooper, tweeter, twirler, twister, underwriter, upper, videorecorder, voucher, walker, webmaster, wide receiver, windsurfer, winger, wing player, winner, woofer, wrangler, yorker youtuber. Zellweger.

\section{-ero $[=50]$}

bedesemero, bikero, bloguero, bluesero, BMXero, canicrossero, choppero, clinero (o klinero), chutero, comixero, cuáquero, flipero, folkero, funero, futinero, golfista, guaspero, hardrockero, beavymetalero, hiphopero, intervinero, jazzero, jetsetero, jipiero, jonronero, killerloopero, marketinero, mitinero, mountainbikero, popero, pulpero, punkero, rapero, ravero, riffero, ritmobluesero, rocanrolero/rockanrolero, rockero, samplero, soulero, thrashero, ticketero/tiquero, trailero, trekkero, trialero, tuitero/twittero, tunero, windsurfero, winstonero, youtubero.

$$
\text { -ista }[=50)
$$

autostopista, beisbolista, bestsellerista, bluesista, clubista, basquetista, bobleighista, cartoonista, cebeista, chartista, comixta, crolista, dumpinista, escautista (escultista) fashionista, finnista, flysurfista, folklorista, fosburista, futbolista, gimkanista, golfista, grupista, harleysta, jazzista, jingoista, jumbista, junglista, kitesurfista, lakista/laquista, lobbysta/lobista, marketista, revivalista, rockista, skiffista, sidecarista, snipista, sportinguista, squashista, surfista, steeplista, tenista, trade-unionista, turfista, turista turntablista, warrantista, waterpolista, windsurfista, yupista, zapista. 
-ING [= 379]

action painting, ACW Climbing, airbagging, anti-aging, anti-doping, antidumping, antifading, aquajogging, aquaplaning, aquarunning, aquaspinning, aquastretching, [baby-sitting, backchecking, backing, ball handling, barebacking, bar gaming, bboying, benchmarking, benzing, billing, blistering, boarding, boardsailing, boating, bodybuilding, body checking, body-painting, bodysurfing, boling, booking, booling, booting, bouldering, bowling, branding, brainstorming, breakdancing, briefing, browning, brushing, bullying, bumping, bundling, bungee jumping, bunging, butt-ending, camping, camping caravaning, canoeing, canting, caravaning, carding, car sharing, carving, casting, catering, catfighting, charging, clearing, climbing, cloning, clubbing, coaching, cocooning, colchoneting, compak sporting, conduct warning consulting, coopering, coping cottaging, country skiing cracking, craving, cross country, cross-dressing, crossing-over, crosstraining, crowbacking crowdfunding, crowding, crowdbacking, crowdsourcing, cruising, curling, cutting, cyber-bulling, cycling, dancing, darling, dating, dating show, disco-bowling, dogging, downshifting, dribbling, drinking, dripping, dubbing, duck diving duffing dumping, easy listening, edredoning, elbowing, expecting, face lijting, factoring, fading, fighting fingering, fisiotraining fist fucking, fisting, fixing, flexions kipping, footing, forechecking, free climbing, free-riding, funboarding, funding, furtling, gaming, goming, graining, grooming, backing, halling, handling, happening, happy ending, headbanging, beadbunting, hearing, belding bidrocracking, bobdaying bolding, bot cycling, booking, burling, hydrozorbing, ice yachting, icing, indoor cycling, indoorwalking, , infielder, inland casting, in-line skating, inning, insider, interval training, jam stretching, jetskiing, jigging jogging, jumping, karting, kickboxing, kiteboarding, kneeing, land yachting, leasing, legging, lemming, lifting, lift training, living lobbying, loofing, looping, mailbobming, maripiercing, maribuilding, maspreading, marketing, mastering, matchmaking, meeting, mentoring, merchandising/merchandaising, metring, microblogging, missing, modeling, moshing, mountain boarding, multiloving, mushing, mystery shopping, networking, opening, outdoor training, outing, outsourcing, overbooking, packaging, paragliding, parapenting, passing, passing shot, peeling, peeping-show, personal training, pesca light, spinning, petting, 
phishing, phreaking, phubbing, piercing, pilling, piloxing, piping, pitching, planking planning, pole bending, popping, power lifting, pressing, puenting, pudding, punching bag, puching/punching, punting, pushing ball, putting, putting green, ranking, rading, rating, reestiling, reforming, regifting, relaxing, renting, restyling, revolving, rimming, rafting, rolling, rubbing, running, sailing, sampling, sandboarding, sclaffing sexting, scoring, scouting, screening, sea jumping, seawatching, seeding, shaping, shooting, shooting compact, shoot wrestling, shopping, show jumping, silla gaming, skateboarding, skating, skiflying, skijöring, ski jumping, skipping, ski yatching, slashing, sliding,smoking, snaking, snorkeling, snowballing, snowsailing, snowshoeing, snowtubing, soling, spamming, spanking, sparring, spearing, speed biking, speed sailing, sex-boxing, shadow boxing, shanking, spalding wedge, speed skiing, spinning, splitting, sponsoring, sporting,spotting, squatting, staking, stalking, standing, starting block, starting gate, starting players, starting Price, stealing, steep skiing,stepping, still fishing, strapsurfing, streaking/ estriquin, streaming, stretching, stripping, styling, surf-casting, surfing, surf-riding, suspension training, swapping, swinging, tackling, tagging, tagging up, tailing, tech training, teeing, teeing ground, telemarketing, teleworking, thai boxing, time-sharing, timing, toasting, tobogganing tooping topping, Total Body Conditioning, total grappling, total training, touring, trading, training, tracking, trampling, trampolining, trap shooting, travelling, trekking, trifoiling, trimming, tripping, trunking, tumbing, tumbling, tuning, turning, twerking, twirling, twirling baton, two minutes warning, underwriting, underwelling, upwelling, vending, video modelling, wakeboarding, warning, water skiing, wave jumping, wave riding, windoping, windsurfing, whipping, windsurfing, wobbing, working, wraping, wrestling, yachting, yearling, yngling zapping. Zorbing.

Recepción: 02/10/2020

Aceptación: 14/01/2021 